\title{
AVALIAÇÃO COMO PODER REGULADOR: A CONCEPÇÃO DE PROFESSORES DE PEDAGOGIA.
}

\author{
Evaluation as power regulator: conception of pedagogy 'teachers
}

\section{Evaluación como Gobernador de Alimentación: el Diseño de Profesores de Pedagogía}

\author{
Vera Lúcia da Silva Almeida ${ }^{1}$ \\ Mara Regina Lemes De Sordi ${ }^{2}$
}

\begin{abstract}
RESUMO:A avaliação como força histórica, cultural e política, provoca reflexos na prática do cotidiano escolar, apresenta-se como um poder instituído e se faz necessário refletir sobre suas representações e valores para o profissional da educação. O objetivo deste artigo é discutir sobre avaliação como poder regulador, a partir das concepções de professores sobre a avaliação escolar em comparação com o projeto político pedagógico. Foi realizada uma pesquisa com vinte professores de um curso de Pedagogia, perguntando sobre a concepção de avaliação frente ao projeto pedagógico institucional. De modo geral os professores responderam que entendem a avaliação desconectada com o projeto político, e que, no entanto deveria ter uma ação integrada, com participação mais intensa do próprio docente para os processos avaliativos com os alunos. Avaliação entendida como objeto de poder quase sempre gera conflitos, ansiedades, transtornos e consequentemente, questões entrelaçadas nas relações entre professores e alunos, e análises provocativas, entender a concepção de professores sobre a avaliação, parece ser um passo importante para refletir possibilidades de mudanças nas relações escolares. Para tanto, orientar as práticas pedagógicas e redefinir continuamente os objetivos, as metas, acadêmicas e em sala de aula, no contexto sócioeconômico e social, exigem estudos e pesquisas científicas.
\end{abstract}

Palavras-chave: Avaliação. Formação de Professor. Ensino Superior.

\section{INTRODUÇÃO}

"O importante e bonito do mundo é isto: que as pessoas não estão sempre iguais, ainda não foram terminadas - mas que elas vão sempre mudando.” Guimarães Rosa.

A discussão sobre poder regulador versus emancipador da avaliação no contexto escolar é parte de uma investigação que trata das concepções e das decisões avaliativas em um Curso de Pedagogia, tendo por referencia as percepções de alunos para refletir sobre o poder da avaliação. (ALMEIDA, 2004).

\footnotetext{
1 Doutoranda em Educação pela Universidade de Sorocaba. Mestre em Educação pela PUC-Campinas. Professora da Associação Educacional Dom Bosco. E-mail: almeida@gmail.com.br.

${ }^{2}$ Doutora em Educação pela Universidade Estadual de Campinas. Realizou pós-doutorado em Planejamento e Avaliação Educacional na PUC-RJ. Professora da Faculdade de Educação, da Universidade Estadual de Campinas. E-mail: maradesordi@uol.com.br.
} 
Consideramos que a avaliação está presente em todo o campo da sociedade e da vida do sujeito. Ao fazer parte da formação do sujeito a avaliação pode interferir nas decisões de problemas, fatos e, até mesmo, em disputas de poder no cotidiano escolar.

Para compreender o contexto do cotidiano escolar, a fim de estudar o poder da avaliação na escola, destacamos a afirmativa de Freire (1980, p. 34): "uma educação, para ser válida precisa considerar a vocação ontológica do homem, vocação de ser sujeito - e as condições em que vive: neste exato lugar, neste momento, neste determinado contexto". Através da visão de contexto e compreensão de suas influências o sujeito vai construindo o seu mundo e, de acordo com as relações estabelecidas, sua avaliação gerada por uma reflexão é transformada em ação.

A reflexão conduz o sujeito à análise de seus valores, exigindo-lhe uma resposta aplicada na busca de entendimento dos fins que orientam sua prática social e dos fins que deverão vir a orientá-las.

A reflexão no campo avaliativo é uma ação situada que julga, criticamente, os valores vigentes e, não raro, auxilia na proposição de outros. É fruto de um tempo e um espaço definido, mas, desde que estabelecido, oferece também limites e contornos ao processo histórico do sujeito.

A avaliação permeia os valores de uma determinada educação, ora confirmando sua validade ora sua reconstrução. Sendo o sujeito marcado por rupturas, por cisões internas, assujeitado a sociedade cujos valores e representações se tornaram questionáveis, não há como avaliarmos de forma homogeneizante.

A avaliação pode se constituir numa resposta da sociedade à dupla exigência de refletir de forma crítica e explicar os valores e suas representações, tornando-os inteligíveis, ou ao menos aceitáveis para os sujeitos que dela participam. É também um modo de aprender, escrever, imaginar, estudar, participar ou não, e de mandar e obedecer.

Se as reflexões transformam-se em ações e, estas, por sua vez, geram novas reflexões, logo, a avaliação é "reflexão permanente do educador sobre sua realidade, e acompanhamento, passo a passo, do educando, na sua trajetória de construção do conhecimento" (HOFFMANN, 1991, p. 20). A reflexão sobre as experiências vividas no processo de aprendizagem possibilita a construção de novos significados que vão sendo construídos e atribuídos a essas experiências, resinificando assim, a aprendizagem, o conhecimento, o pensar e o agir.

\section{Revista de Ciências Humanas | FW | v. 15 | n. 24 | p. 73-83 | Jul. 2014 Recebido em: 13 mar. 2014 Aceito em: 24 jul. 2014}


A avaliação da avaliação é uma nova forma de discutir a avaliação em um 'tempo novo'. Tempo de providenciar o intercruzamento de dados que possa levar à melhoria dos cursos e da Instituição, inclusive, fazendo com que a Universidade assuma seu papel na sociedade. (DE SORDI, 1995, p. 122)

Nessa ótica, a avaliação é reflexão transformadora da ação. Como toda ação possui intencionalidade e, como avaliar é uma atividade inerente à ação, concluímos que o processo de avaliação como instrumento de aprendizagem, deve gerar ação e, por conseguinte, terá consubstanciado em si a necessidade de ser avaliado. Ou seja, a ação de avaliar carece de avaliação para que a mesma possa renovar-se constantemente diante das novas situações de aprendizagem.

(...) a instituição escolar dota de significado ao que entendemos por realidade educativa e, por meio de seus procedimentos, entre os quais a avaliação, dota de sentido real os próprios conceitos com que pensamos a prática. A avaliação, por sua vez, dota de conteúdo a ideia de 'excelência escolar', que serve para falar do que funciona melhor ou pior. (GIMENO SACRISTÁN; GÓMEZ, 1992, p. 32),

A prática avaliativa, desse modelo, que indica o pior e/ou o melhor, é conservadora, e tem uma ação autoritária, pois seu caráter pertence à essência dessa perspectiva, exigindo controle e enquadramento dos sujeitos nos moldes previamente estabelecidos de equilíbrio social, seja pela utilização de coações explícitas seja pelos meios ou pelas heranças culturais. Nesse modelo, a avaliação é um instrumento disciplinador não só das condutas cognitivas como também sociais, no contexto Institucional.

Diante de tais considerações, lembramos Luckesi (2000, p. 36), ao afirmar que "os mais aptos, socialmente, permanecem na situação de mais aptos e os menos aptos, do mesmo ponto de vista, permanecem menos aptos". Esse ritual pedagógico não propicia modificação na distribuição social dos sujeitos nem auxilia na transformação social. Pelo contrário, a avaliação desempenha, nas mãos do professor, o papel disciplinador, próprio do modelo social-conservador.

Com o uso do poder, via avaliação discriminatória, o professor, representado pelo sistema, "enquadra" os alunos, dentro de uma escala social, criada e estabelecida. O processo avaliativo, que deveria ser dinamizador de oportunidades, impulsionador e catalizador do potencial humano reduzem os sujeitos a uma escala numérica e objetal.

\section{Revista de Ciências Humanas | FW | v. 15 | n. 24 | p. 73-83 | Jul. 2014


A avaliação deve ser algo sempre em construção, jamais definitivo; seu ponto de partida é o respeitar a vida, refletir sobre o vivido em todas as dimensões. Foucault (2001, p. 106), ao falar de poder, afirma que: "É a individualização do espaço, a inserção dos corpos em espaço individualizado, classificatório, combinatório, exercendo seu controle, não sobre o resultado de uma ação, mas sobre seu desenvolvimento.”.

Este processo de hierarquização implica a vigilância perpétua e constante dos indivíduos. Não basta olhá-los às vezes ou ver se o que fizeram é conforme a regra. É preciso submetê-los a uma pirâmide de olhares, um registro contínuo, anotação do indivíduo e transparência da informação de baixo para cima, de modo que o cume da pirâmide disciplinar nenhum detalhe, acontecimento ou elemento disciplinar escape a esse saber.

No sistema classificatório o exercício do poder se dá num conjunto de técnicas pelas quais os sistemas de poder vão ter alvo e resultado os indivíduos em sua singularidade. É o poder de individualização que tem a prova, o exame, e ou qualquer outro tipo de avaliação escolar como instrumento fundamental. O "exame", a avaliação escolar, é a vigilância permanentemente classificatória, que permite distribuir os indivíduos, julgá-los, medi-los, localizá-los e, por conseguinte, enquadrá-los. Através do exame, a individualidade torna-se um elemento pertinente para o exercício do poder.

Ainda em Foucault (2001), sobre os mecanismos disciplinares, entre eles: hospital, caserna, prisões, e a escola, todos com a função de disciplinamento, enquadrar os indivíduos às condições de obediência, mesmo que para isso use de força, medicamentos e ou classificações educativas que subjugam o indivíduo.

A justificativa para o uso desses mecanismos tem raízes nas razões econômicas, o preço atribuído ao indivíduo, o desejo de evitar que as "epidemias" se propaguem aplicam enquadramento disciplinar a que estão submetidos os hospitais, escolas e outras instituições de aprisionamento. E, então, a formação de um professor deve-se, por um lado, à disciplinarização do espaço escolar, e, por outro, à sua transformação, com uso do saber e da prática docente, para disciplinar e ou libertar o aluno. Isto significa a exigência da aprendizagem ser compreendida como um fenômeno natural, características observáveis, preparação e desenvolvimento como um todo.

O indivíduo "sadio", bem orientado, quando submetido a certas ações do meio, é o suporte de prova (teste), fenômeno limite do homem. Diante disso, a aula bem conduzida, o respeito ao aluno, a revisão dos conteúdos, a preparação consciente da prova, o fator tempo, a

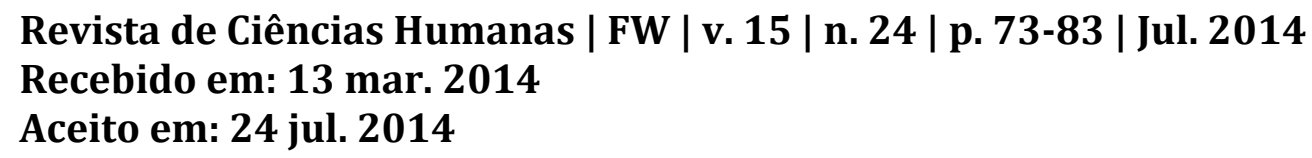


negociação com o aluno, a discussão dos critérios, constituem a segurança ao aluno na realização das provas. São esses critérios que vão constituindo, na medida em que a avaliação é concebida como um fenômeno natural obedecendo às leis naturais. Ou será que esses fenômenos, distintos em sua origem, vão poder ajustar com o aparecimento de uma disciplina (prova autoritária) que terá por função assegurar à esquadriamento, a vigilância, a disciplinarização do mundo confuso do aluno e da dificuldade (insegurança), como também transformar as condições do meio em que os "pacientes/alunos" são colocados?

O importante a destacar é que essas reflexões entre normas e critérios são fruto de uma construção social, difundidas como se fossem a única forma possível de conceber a realidade. E a partir deles são tomadas decisões e definidas ações que afetam o desenvolvimento social dos indivíduos.

\footnotetext{
O poder político da avaliação consiste em distribuir um ao lado dos outros, isolá-los, individualizá-los, vigiá-los um a um, contestar o estado de "saúde" de cada um, ver se está vivo ou morto e fixar, assim, a sociedade em um espaço esquadrinha, divide inspecionado, percorrido por um olhar permanente e controlado por um registro, tanto quanto possível completo de todos os fenômenos. (FOUCAULT, 2001, p. 89)
}

Diante dessa análise, o saber do professor, contribui para a aprendizagem do aluno, ou será que a avaliação realmente educativa não pode se limitar a um papel controlador e de afirmação de heteronímia e da competitividade individual, com caráter político e ético a serviço da construção da autonomia?

Na ótica de De Sordi (1995), o conceito que se insere no campo educacional está estreitamente vinculado ao próprio conceito de educação e de sua referência social. O docente,

(...) deve ser um agente capaz de provocar mudanças no processo ensinoaprendizagem/educação/avaliação, através de ações baseadas nos pressupostos do saber técnico-científico e da consciência do seu papel social-educacional. A ação professor deve dar-se a partir da congregação de esforços com a equipe multifuncional e com a própria clientela. (DE SORDI, 1995, p. 30)

Ainda na percepção do autor, a prática de avaliação deve constituir-se em um ato dinâmico, com natureza processual, ocorrendo de modo coparticipado, no qual o professor e aluno, através do diálogo e da interação respeitosa, assumindo seus papeis, comprometem-se

\author{
Revista de Ciências Humanas | FW | v. 15 | n. 24 | p. 73-83 | Jul. 2014 \\ Recebido em: 13 mar. 2014 \\ Aceito em: 24 jul. 2014
}


com a construção do conhecimento e com a formação de um profissional "competente", apto a prestar assistência e despertar o interesse do aluno.

Nesta perspectiva, conhecer as concepções de avaliação da aprendizagem dos professores e seu significado no Ensino Superior, e avaliar as decisões relativas aos instrumentos de avaliação adotados e sua coerência com as concepções de avaliação, implica compreender este fenômeno de modo global, fugindo de visões atomizadas.

Compreender a avaliação é também necessário compreender seus papéis no universo político mais amplo. A avaliação da educação superior não pertence, então, ao interesse privado, mais sim ao universo de valores do âmbito público. Um processo mais ético que técnico, não é feita para benefício dos indivíduos e somente das partes implicadas, mas sim é prática social de interesse da sociedade em geral. (DIAS SOBRINHO, 2000, p. 7).

A dimensão ética e política da avaliação na universidade se remetem essencialmente ao compromisso social de formação. Dentro dessa perspectiva, a universidade tem uma irrecusável responsabilidade pública, que consiste especialmente na formação de indivíduos autômatos e cidadãos plenamente ativos na sociedade e na história. O sentido ético da avaliação consiste, pois, em auxiliar a universidade a conferir um sentido profundamente humano, portanto social ao desenvolvimento técnico e econômico. Isso significa assegurar prioridade à ética e à política sobre a técnica e sobre a esfera econômica a que grande parte técnica visa servir.

Ainda nessa direção Dias Sobrinho, comenta que.

\begin{abstract}
Não pode se realizar meramente como controle, tampouco deve operar com a lógica do prêmio e do castigo ou do vigiar e punir. Sua intencionalidade, seu sentido hegemônico, ou seja, sua direção intencionalmente assumida é a busca da construção e da consolidação da melhoria das funções fundamentais da instituição educativa, que passa pela elevação da consciência política e pedagógica dos atores institucionais e pelo aumento da profissionalização docente. (DIAS SOBRINHO, 2002, p. 5).
\end{abstract}

Bertagna (1997) corrobora a afirmação de outros estudos, de que “[...] a sala de aula é um palco de conflitos, onde os processos de avaliação institucional, disciplinar e de valores jogaram papel central”.

Ao utilizar a sala de aula como palco, selecionamos a avaliação e seus instrumentos/procedimentos, a atitude/comportamento para apresentar as concepções de avaliação dos professores do Curso de Pedagogia, da Associação Educacional de Resende/RJ.

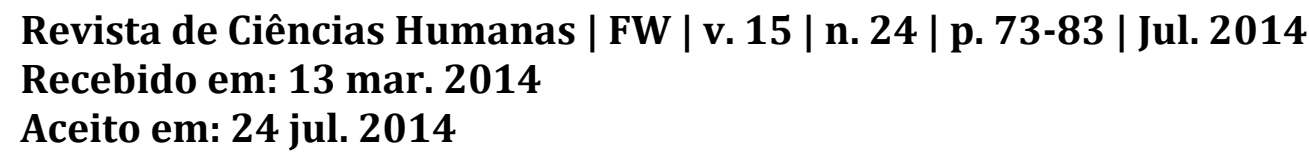




\section{CONCEPÇÃO DE PROFESSORES SOBRE AVALIAÇÃO DE ALUNOS}

Para coleta de dados, utilizamos o método de entrevista com professores do Curso de Pedagogia, da Associação Educacional de Resende/RJ. Elaboramos um questionário com seis questões abertas, sobre o que é avaliação, as representações de avaliação e coerências entre avaliação e o projeto político pedagógico da instituição.

Entrevistamos e gravamos as falas de vinte professores que atuam no Curso de Pedagogia.

Identificamos o percentual relativo ao tempo de atuação dos docentes no magistério, para maior entendimento sobre o perfil dos sujeitos pesquisados:

- $58 \%$ dos professores possuem mais de dez anos de atuação no magistério;

- $29 \%$ dos docentes estão atuando no curso há pelo menos dez anos;

- $13 \%$ possuem mais de vinte anos de atuação no magistério.

A maioria dos professores possui experiência significativa no magistério. Logo, supomos que tenham conhecimento e desenvoltura na organização do trabalho pedagógico. Por essa ótica, o professor, ao tomar decisões, ao agir em prol do desenvolvimento do aluno, pode evitar que a avaliação seja, somente, classificatória, burocrática e com uso de instrumentos voltados para medir o conhecimento.

Os professores entrevistados revelam uma concepção de avaliação que almeja a superação do autoritarismo. Em suas falas, expressaram ações concretas de avaliação baseadas em concepções mais condizentes com um modelo fundamentado de educação e com a política pedagógica da Instituição. Acreditam num repensar do processo avaliativo permeado e comprometido com a educação participativa. Esse entendimento é reforçado por Freitas (2003, p. 30), quando afirma que: “Testes e provas são apenas indicadores tênues desses processos informais que estão implícitos nas decisões avaliativas tomadas que revelam concepções de mundo".

Isso mostra que o trabalho pedagógico também passa pela relação de produção de conhecimento e de poder em sua existência e que o professor sem o aluno não dá conta de todas essas questões.

$\mathrm{Na}$ organização de seus processos de ensinar e aprender, os professores se pronunciaram da seguinte forma:

Revista de Ciências Humanas | FW | v. 15 | n. 24 | p. 73-83 | Jul. 2014 Recebido em: 13 mar. 2014 Aceito em: 24 jul. 2014 


\footnotetext{
"Construo instrumento com conhecimento".

"Trabalho produção grupal, completando a avaliação, mesmo correndo o risco da subjetividade/interferência e os resultados positivos que têm sido animadores".

"Uso práticas com questões variadas em várias turmas".

"Incentivo à produção bem preparada".
}

Tais depoimentos dos participantes da pesquisa demonstram que há uma proposta de construção avaliativa junto ao discente, uma busca de aprofundamento do conhecimento, a preocupação com os resultados significativos e o estabelecimento da relação entre ensino-aprendizagem. Há relevância do conteúdo para os alunos quando o professor dá opção para escolherem os temas do seu interesse para trabalhar.

Observamos a valorização do diálogo, o que significa abertura, dinamicidade e envolvimento com o aluno. Ao mesmo tempo identificamos que a produção do aluno é relevante para o trabalho escolar.

A avaliação utilizada por esses profissionais é trabalhada de forma que não se concentre apenas na medida. A nota passa a ser uma das partes da avaliação e não a totalidade do resultado.

De modo geral os professores responderam que entendem a avaliação desconectada com o projeto político. No entanto, segundo eles, deveria ter uma ação integrada, com participação mais intensa do próprio docente para os processos avaliativos com os alunos. Avaliação entendida como objeto de poder quase sempre gera conflitos, ansiedades, transtornos e consequentemente, questões entrelaçadas nas relações entre professores e alunos, e análises provocativas, entender a concepção de professores sobre a avaliação, parece ser um passo importante para refletir possibilidades de mudanças nas relações escolares.

\section{CONCLUSÕES}

Compreendemos a avaliação como uma ação intencional do processo educativo (projeto). Uma avaliação como instrumento de impulso da aprendizagem, enquanto reflexão sobre a mesma, possibilitando a própria ação.

Não é qualquer intencionalidade que interessa, levando-nos a fazer opção por um tipo de formação e consequentemente por um tipo determinado de sujeito. Quando a opção é de

\section{Revista de Ciências Humanas | FW | v. 15 | n. 24 | p. 73-83 | Jul. 2014 Recebido em: 13 mar. 2014


formarmos sujeitos críticos, criativos, autônomos, capazes de pensarem e agirem por si, capazes de transformar suas relações interpessoais e sociais, se construírem como indivíduos e seres sociais, temos que refletir sobre o tipo de ação educativa e que pode contribuir para sua formação, ou o tipo de aprendizagem que eles devem empreender para se constituírem como tal.

Na representação simbólica do poder regulador versus emancipador da avaliação, é possível perceber contradições nas representações que permitem repensar ações em conjunto para a obtenção de resultados que objetivam a aprendizagem e novos saberes.

A preocupação enquanto educador (a) em iniciar o trabalho pedagógico em parceria com os demais profissionais de áreas afins e/ou das diversas profissões, para consolidar saber sistematizado e orientado com a finalidade de articular outras trocas de conhecimentos, parece ser papel do educador.

O que pretendemos evidenciar é que a análise do poder regulador versus emancipador da avaliação pode servir de reflexão para o desempenho da prática pedagógica docente, como alerta de atitudes e comportamentos arbitrários nos diversos níveis de ensino.

Os estudos indicam fatos carregados de incertezas referente à avaliação no contexto escolar há parâmetros de concepções a partir de literatura e dos modelos de avaliação praticados nas instituições de ensino, confrontando com a percepção do aluno. Isso nos mostra o inacabamento da pesquisa em prol da temática.

Programar mudanças, provocar debates e desvendar os silêncios empacotados ou enlatados para fins "pedagógicos", podem contribuir para posicionamento diante da temática avaliação e poder.

Respeitar os conhecimentos dos estudantes bem como suas experiências pode favorecer nas suas manifestações e, consequentemente provocar maior diálogo em sala de aula, condição para uma aprendizagem que considera o outro e estabelece respeito à diversidade.

A partir desta analise, destaca-se a necessidade dos cursos de formação de professores para apresentarem a avaliação visando fomentar as aprendizagens carregadas de pertinência social.

Dos contextos de discussões e pesquisas consideradas cruciais para a formação de professores e para a educação superior, espera-se dos educadores posicionamentos críticos,

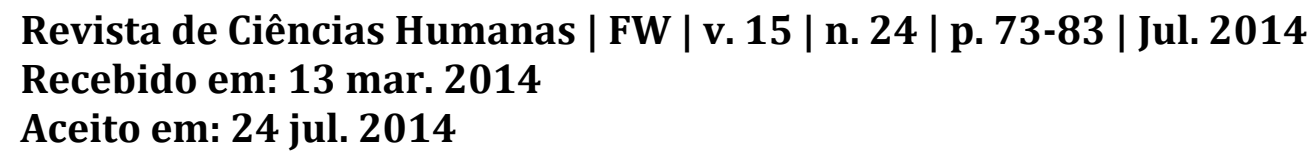


articulando teoria- prática- ação-reflexão, numa dimensão dialógica, subsidiada com caráter político, ético, voltados para as dimensões educacionais.

\begin{abstract}
Evaluation as historical and political strength, cultural, causes reflections in everyday school, presents itself as an institutional power and it is necessary to reflect on their representations and values for professional education. The objective of this paper is to discuss how to review regulatory power, from the conceptions of teachers about school assessment compared with the political pedagogical project. A survey of twenty teachers of a pedagogy course, asking about the concept of evaluation against the institutional educational project was performed. Generally teachers responded that they understand the assessment disconnected with the political project, which however should have an integrated action, with more intense involvement of teachers themselves to evaluation processes with students. Evaluation understood as an object of power almost always generates conflicts, anxieties , disorders and therefore issues intertwined in relations between teachers and students, and provocative analysis, understand the concept of teachers on evaluation, seem to be an important step to reflect possible changes in school relations . To do so, guide pedagogical practices and continually redefine the objectives, goals, academic and classroom, in the socio -economic and social context, require studies and scientific research.
\end{abstract}

Keywords: Evaluation. Teacher Training. Higher Education.

RESUMEM: La evaluación como fuerza histórica y política, cultural, provoca reflejos em La escudela todos os lós dias, se presenta como um poder institucional y ES necessário reflexionar sobre lãs representacionais y lós valores de lá educación Professional. El objetivo de este trabajo es discutir lá forma de revisar lá potestade regulamentaria, a partir de las concepciones de los profesores acerca de la evaluación de la escuela en comparación con el proyecto político-pedagógico. Se realizó una encuesta de veinte profesores de un curso de pedagogía, preguntando por El concepto de evaluación en contra Del proyecto educativo institucional. General mente lós professores responderam que ellos entienden La evaluación desconectada com El proyecto político, no obstante, debería tener una acción integrada, con más intensa participación de los propios docentes a los procesos de evaluación con los Estudiantes. La evaluación entendida como un objeto de poder casi siempre genera conflitos, ansiedades, trastornos y, por tanto, cuestiones entrelazadas en las relaciones entre profesores y alumnos, y El análisis provocativo, entender El concepto de los docentes sobre La evaluación, parece ser un paso importante para reflejar los posibles cambios en las relaciones escolares. Para ello, orientar las prácticas pedagógicas y redefinir continuamente lós objetivos, metas, académico y El aula, en El contexto socio- económico y social, requieren estudios e investigaciones científicas.

Palabras clave: Evaluación. Formación Del Professorado. Educación Superior.

\title{
REFERÊNCIAS
}

ALMEIDA, Vera Lúcia da Silva. Um estudo das concepções e das decisões avaliativas no curso de pedagogia. Dissertação de Mestrado, PUC- Campinas, 2004.

\author{
Revista de Ciências Humanas | FW | v. 15 | n. 24 | p. 73-83 | Jul. 2014 \\ Recebido em: 13 mar. 2014 \\ Aceito em: 24 jul. 2014
}


BERTAGNA, Regiane Helena. Avaliação da aprendizagem escolar: a visão de alunos de quartas e quintas series do primeiro grau. 1997. Dissertação (Mestrado em Educação) Faculdade de Educação, Universidade Estadual de Campinas, Campinas, 1997.

. A prática da avaliação no ensino superior: uma experiência na enfermagem. São Paulo: Cortez, 1995.

DIAS SOBRINHO, J. Avaliação da Educação Superior. Petrópolis: Vozes, 2000.

Universidade e avaliação: entre a ética e o mercado. Florianópolis: Insular, 2002.

FOUCAULT, Michel. Microfísica do poder. Rio de Janeiro: GRAAL, 2001.

FREIRE, P. Conscientização: teoria e prática de libertação. São Paulo: Moraes, 1980.

FREITAS, Luiz Carlos de. Ciclos, seriação e avaliação: confronto de lógicas. São Paulo: Moderna, 2003. (Coleção Cotidiano Escolar).

SACRISTÁN, J. Gimeno; GÓMEZ, A. Pérez. Comprender y transformar lá enseñanza. Madrid: Adiciones Marata, 1992.

HOFFMANN, Jussara M. L. Avaliação: Mito e desafio. Uma perspectiva construtivista. Porto Alegre: Educação e Realidade, 1991.

LUCKESI, Cipriano Carlos. Avaliação da aprendizagem escolar. 2. ed. São Paulo: Cortez, 2000.

Revista de Ciências Humanas | FW | v. 15 | n. 24 | p. 73-83 | Jul. 2014 